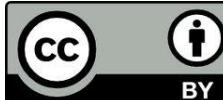

\title{
COMBATER OS ESPÍRITAS? MISSÃO DO BISPO
}

\author{
Combat the spiritis: mission of the bishop
}

\author{
Flamarion Laba da Costa \\ Universidade Estadual do Centro-Oeste (UNICENTRO) \\ Guarapuava - PR - Brasil \\ Doutor \\ flamarionlaba@yahoo.com.br
}

\begin{abstract}
RESUMO: O objetivo deste artigo é analisar o discurso de uma autoridade católica na cidade de Ponta Grossa, estado do Paraná. Esta autoridade foi D. Antonio Mazzarotto nomeado primeiro bispo para a recém-criada diocese de Ponta Grossa. D. Antonio, desenvolveu um trabalho de acolhimento, alerta e cuidado preocupando-se com os profitentes da territorialidade da sua diocese, cujo território era bastante extenso. Sua preocupação religiosa voltou-se para a presença dos Espíritas, no estado do Paraná e consequentemente na cidade de Ponta Grossa. Através das suas Pastorais, lançava um alerta aos sacerdotes para que vigiassem e orientassem o "rebanho" para que ficassem afastados de todas as práticas, obras e participar desta prática diabólica, construindo um discurso de oposição e combate aos espíritas no território da sua diocese.
\end{abstract}

Palavras chave: Religião; espiritismo; catolicismo.

ABSTRACT: The aim of this article is to analyze the discourse of a catholic authority in the city of Ponta Grossa; PR. Don Antonio Mazzaroto was the first bishop appointed to the newly created diocese of Ponta Grossa. Don Antonio developed a welcoming, alertness and care work for the catholic population of his diocese, whose territory was quite extensive. His religious concerns was directed to the presence of spiritists in the state of Paraná and as a consequence in the city of Ponta Grossa. Through his pastoral activities, Don Antonio sent an alert so that priests watched over and guided their "flock" and kept them away from all practices, work and participation in the diabolic practice of Spiritualism. With these actions, Don Antonio developed a discourse of opposition and combat against the spiritist population of his diocese.

Keywords: Religion; Spiritism; Catholicism. 
"Nunca como hoje a religião foi objeto de tantos estudos, por parte das mais variadas (do ponto de vista metodológico) disciplinas" (FILORAMO; PRANDI, 1999, p. 5).

Religião, um tema que quando abordado provoca as mais variadas reações em diferentes grupos de pessoas. A religião começou a ser pesquisada pela academia no século XIX e, segundo Mircea Eliade, “A primeira cátedra universitária de história das religiões foi criada em Genebra em 1873" (ELIADE, 1992, p. 1). A esta, seguiram-se outras universidades, em diferentes países, que foram instalando estudos sobre os mais diferentes conceitos religiosos, causando espanto na sociedade da época que leigos pesquisassem as religiões adotando métodos científicos, não pertencendo a corpos especializados - sacerdotes/pastores.

Max Müller, considerado o fundador da disciplina, em obra publicada em 1873 citava que, "Es imposible em nuestros dias hablar de religión sin que alguien se ofenda. A los ojos de muchas personas, la religión es um objeto que, por su carácter sagrado, está fuera del alcance de las investigaciones y métodos científicos” (MÜLLER, 1945, p. 9).* Observa-se que, a partir da segunda metade do século XIX, iniciou-se de forma oficial os estudos e pesquisas acadêmicas sobre religiões.

Para o final do século XIX e início do XX, historiadores, filósofos e sociólogos também desenvolveram pesquisas sobre religião, compondo um quadro teóricometodológico, estudando e analisando os mais diferentes conceitos doutrinários religiosos. Mais recentemente, surgiu entre as áreas que estudam religião a Geografia da Religião, com uma abordagem voltada para a espacialidade, quer empírica (em espaços materiais), quer simbólica (no plano espiritual).

Nesse sentido, cabe a uma Geografia da Religião, que vasculhe além das formas aparentes, uma análise mais profunda do fenômeno religioso; considerando as dimensões não visíveis do devir humano também aqueles aspectos mais íntimos da experiência religiosa. (PEREIRA, 2014, p. 35).

Identifica-se mais uma disciplina dedicada ao estudo das religiões, o qual se

\footnotetext{
* É impossível em nossos dias falar de religião sem que alguém se ofenda. Aos olhos de muitas pessoas, a religião é um objeto que, por seu caráter sagrado, está fora do alcance das investigações e métodos científicos. (Tradução nossa).
} 
reveste de grande importância pela complexidade que representam estas pesquisas.

Quando estudamos e pesquisamos religião(ões), estamos abordando um assunto que, em virtude de seu conteúdo emocional e doutrinário e que se faz presente em todas as classes sociais, torna-se de extrema importância. Sempre que falamos em religião estamos nos referindo ao sagrado, ao invisível, à divindade, ao sentimento, ao não racional, à contemplação, ao mistério e outros adjetivos possíveis, aplicados por vários pesquisadores das religiões, não descartando o poder e a administração dos bens sagrados. Todos os itens aqui relacionados são praticados pelo ser humano, sendo este quem organizou e criou ritos e teologias para a explicação do mundo espiritual, ou do mysterium tremendum, segundo Rudolf Otto (OTTO, 2005, p. 22).

Outra abordagem é da materialidade das religiões, visto que os deuses, personagens santificados e seres espirituais pertencem ao "mundo invisível", representando o imaterial, e são materializados nos templos e demais locais para a prática de diferentes cultos. São elaborados códigos e normas que, colocadas em prática, vão materializar o imaterial (BERGER, 1985, p. 38). Na abordagem religiosa, os conceitos de racionalidade e a não racionalidade compõem outro conteúdo que também é debatido pelos pesquisadores, visto que as práticas religiosas, nesta perspectiva, materializam o imaterial e se "harmoniza na medida do possível o irracional e o racional", (DUPRONT, 1976, p. 81).

É a essa abordagem ou crença nessas divindades que o ser humano tenta explicar e provar a sua existência, mas com atos criados, organizados e praticados pelo ser humano. Segundo Comte-Sponville, "Comecemos pelo mais fácil. Deus, por definição, está além de nós. As religiões não. Elas são humanas - humanas demais, dirão alguns e, como tais, acessíveis ao conhecimento e a crítica" (COMTE-SPONVILLE, 2007, p. 11). Peter Berger também qualifica a religião como um empreendimento humano, pois é por meio deste ser, "seres religiosos", que toma forma empírica, materializado nas ações dos profitentes. (BERGER, 1985, p. 38).

Durkhein, citando Max Müller, diz que existe um esforço "para conceber o inconcebível, para exprimir o inexprimível, uma aspiração ao infinito" (DURHHEIN, 1996, p. 5). O ser humano, com suas ações no campo religioso, organizou um corpo de códigos que disciplinou as práticas religiosas, tornando-as complexas, exigindo a formação e preparação de corpos sacerdotais, responsáveis pela administração e prática 
correta. Para Weber, esses corpos e organizações de pessoas e dirigentes religiosos "passaram ao centro da organização profissional para a 'cura da alma' que, na verdade, ali se originou" (WEBER, 1982, p. 313).

Partindo desta abordagem, o assunto que pesquisaremos no presente texto referese ao discurso do primeiro bispo da cidade de Ponta Grossa, D. Antonio Mazzarotto, dirigido a seus fiéis, mas também aos espíritas e suas práticas nesta cidade. A Diocese de Ponta Grossa foi instituída através da Bula "QUUM IN DIES NUMEROS”, emitida pelo Papa Pio XI, em 10 de maio de 1926, tomando posse D. Mazzarotto em 03 de maio de 1930.

O espaço territorial desta diocese abrangia extensa área, que perfazia 56.550 $\mathrm{km}^{2}$, abrangendo 12 paróquias: Ponta Grossa, Castro, Cruz Machado, Guarapuava, Imbituva, Ipiranga, Ivaí, Palmas, Prudentópolis, Rio Claro, Tibagi e União da Vitória. A administração e o controle de tão vasta área, aliada à dificuldade de transportes na época, com meios de locomoção lentos e caminhos difíceis, fazia com que os bispos encontrassem grandes dificuldades para a visitação, utilizando como veículo de comunicação, com as várias paróquias componentes da sua diocese, as suas pastorais, que tinham como objetivo orientar e cobrar dos párocos e dos demais membros que compunham o clero o reto caminho e a melhor forma de vigiar os profitentes nos ensinamentos da Igreja Católica. Como as paróquias surgem como pontos catalizadores para os fiéis, para a prática de atos sagrados e também profanos (festas religiosas), tornam-se referência para a transmissão do discurso doutrinário institucional do bispo, que será reconhecido pelos católicos (GIL FILHO, 2008, p.122).

A autoridade do bispo em sua Diocese é assegurada pelo Código de Direito Canônico, conforme os Cânon 375 e 381 . De acordo com o Cânon 375 § 1: “Os Bispos que, por divina instituição, sucedem aos Apóstolos são constituídos, pelo Espírito que lhes foi conferido, pastores na Igreja, a fim de serem também eles mestres da doutrina, sacerdotes do culto sagrado e ministros do governo" (C.D.C, 2012, p. 122). Já no Cânon $381 \S 1$, consta a seguinte determinação: “Compete ao Bispo diocesano, na diocese que lhe foi confiada todo o poder ordinário, próprio e imediato, que se requer para o exercício de seu múnus pastoral, com exceção das causas que forem reservadas, pelo direito ou por decreto do Sumo Pontífice, à suprema ou a outra autoridade eclesiástica" (C.D.C, 2012, p. 124). 
Fica definida, desta forma, a autoridade do Bispo em sua Diocese, advinda do Sumo Pontífice, bem como do Direito Canônico, como já citamos. No princípio do poder que uma pessoa exerce no comando de uma organização, Bourdieu afirma que

\begin{abstract}
A eficácia do discurso performativo que pretende fazer acontecer o que enuncia no próprio ato de enunciá-lo é proporcional à autoridade daquele que o enuncia [...] constitui uma autorização quando aquele que pronuncia está autorizado a autorizar, tem autoridade para autorizar (BOURDIEU, 1996, p. 111).
\end{abstract}

A ação dos bispos a frente das suas dioceses ampara-se justamente pelo poder que segundo o Código de Direito Canônico: "Cânon 16 - § 1. Interpretam autenticamente as leis o legislador e aquele ao qual for por ele concedido o poder de interpretar autenticamente". (C.D.C. 2012, p. 33). Fica esclarecido, desta forma, donde advém o poder que os bispos exercem sobre o clero e os profitentes.

Após a abordagem sobre a autoridade e o poder dos bispos, passaremos à análise do discurso de D. Antonio Mazzarotto em relação aos espíritas no espaço territorial da sua diocese, conforme proposição da presente pesquisa. D. Antonio externou uma aversão às práticas espíritas, como ficou demonstrado em algumas de suas pastorais.

As notícias sobre o espiritismo em território brasileiro remontam à época imperial. Segundo relatos, o Jornal Commercio do Rio de Janeiro, publicou pela primeira vez, em 14 de julho de 1853, notícia vinda da Europa, sobe as mesas girantes. Seguiram-se outras notícias em diferentes órgãos da imprensa escrita, em diferentes estados (BARBOSA, 1987, p. 68). Em ato para organizar o movimento espírita em território brasileiro, a 02 de janeiro de 1884, foi fundada a Federação Espírita Brasileira, com sede no Rio de Janeiro, então capital Imperial. Em diferentes estados foram sendo criadas as federações estaduais. No Paraná não foi diferente, a instalação de centros espíritas levou seus dirigentes, a 24 de agosto de 1892, a fundarem a Federação Espírita do Paraná, com sede em Curitiba, capital da então Província do Paraná. Em território brasileiro, os espíritas colocaram em prática - além do espiritual - um trabalho assistencial, a exemplo da distribuição gratuita de homeopatia. Destaque-se que, no Brasil, os espíritas, além de traduzirem para o português as obras de Allan Kardec, publicaram artigos em jornais, livros e folhetos, se referindo ao clero católico no sentido de responder as acusações aos espíritas e criticar as atitudes dos clérigos. (COSTA, 
2001, p. 69).

Na cidade de Ponta Grossa, futura diocese que será comandado por D. Antonio, as primeiras notícias fazem menção que, em 1911, um grupo de militares do $5^{\circ}$ Regimento de Infantaria organizou um grupo para práticas e estudo do espiritismo, intitulado Grupo Allan Kardec. Em 20 de janeiro de 1912, foi fundado o grupo "Espírita Francisco de Assis", a qual fundiu-se o Allan Kardec (Jornal O PROGRESSO, 1912). Na cidade de Ponta Grossa, desde sua organização inicial, os espíritas desenvolveram atividades dirigidas à assistência, a exemplo de outras regiões do território nacional (COSTA, 1995, p. 50). Com relação a essas atividades, alertava D. Mazzarotto: “Com o ouro dos protestantes e com a filantropia dos espiritistas, compram-se as consciências e semeia-se o erro contra a única depositária da sã doutrina e a mestra infalível da verdade, a Santa Igreja Católica" (PASTORAL, 1945, p. 8). Ele demonstrava conhecimento das atividades dos espíritas na cidade sede da sua Diocese, apontando a Igreja como única e verdadeira e assim desacreditar o trabalho dos espíritas.

Pela sequência cronológica e de fatos aqui citados, e como D. Antonio tinha realizado seus estudos como seminarista, exercido o sacerdócio e ministrado aulas em seminário na cidade de Curitiba, era de seu conhecimento a organização e expansão do Espiritismo em diferentes regiões do estado do Paraná. Portanto, consciente da situação em Ponta Grossa de atividade intensa dos espíritas nesta cidade, buscou, através de suas pastorais, construir um discurso de alerta aos fiéis católicos na sua base territorial diocesana e ataques àquelas práticas que considerava heréticas e demoníacas. $\mathrm{O}$ primeiro cuidado de Dom Antônio Mazzarotto foi conhecer seus fiéis; conhecê-los bem, por isso palmilhou a extensão territorial em longas e demoradas viagens na diocese, que abrangia, como já citamos, em 1930, $56.550 \mathrm{~km}^{2}$.

Para Eni Pulcinelli Orlandi, ao discurso religioso se aplica a noção de reversibilidade, quando afirma que não se deve colocar o discursante e o ouvinte em lugares fixos, pois ocorre uma interação entre as posições. Para a autora, isto representa "a troca de papéis na interação que constitui o discurso e o que o discurso constitui" (ORLANDI, 1996, p. 239). Neste tipo de discurso, os homens sempre falam em nome de alguém, e esse alguém é uma divindade que, para os católicos, é Deus. Assim, o clero fala em nome de Deus, Jesus Cristo e dos Santos; enquanto que, para os espíritas, Deus se manifesta e se comunica com os homens por meio dos espíritos que, via 
médium, transmitem seus ensinamentos. O objetivo dos dois é o mesmo: fazer com que seus adeptos se dirijam a Deus, via intermediários que materializam e interpretam a sua fala.

Nota-se, na fala de D. Antonio, que o principal objetivo do seu discurso é de anular a fala dos espíritas. Para isso, vai ressaltar a sacralidade, autoridade e legitimidade da Igreja Católica em todos os sentidos. "A Igreja é, então, tanto lugar sagrado quanto identidade social. Enquanto lugar, é a materialidade do sagrado e, como identidade social, é seu conteúdo per si (GILFILHO, 2008, p. 120, Grifo no original). A agressividade contida no discurso abordava a condição de líder de uma religião, a qual pela tradição todos os habitantes do território da sua diocese - deviam estar praticando. Buscava demonstrar que sua fala continha além da autoridade, características de verdades e do sagrado. "Desse modo, o clero tende a monopolizar o discurso da virtude como forma simbólica de perpetuar a legitimidade da instituição religiosa diante da sociedade" (GILFILHO, 2008, p. 41). É recorrente o discurso das verdades da igreja e das heresias do que estivesse fora do aprisco católico.

Para Pierre Bourdieu, para ser aceito, o discurso estará condicionado a sua identificação objetiva com o grupo para o qual é dirigido, devendo possuir dupla interpretação. Essa dupla interpretação é a de que o dirigente deve se identificar como líder perante o grupo e estar ciente daquilo que o grupo espera dele. Por outro lado, a credibilidade do enunciado exigirá a identificação do grupo com o discurso e, então, reconhecendo a autoridade de quem o produziu, dará condições ao líder de se sobressair e impor sua pregação perante a comunidade (BOURDIEU, 1996, p. 111).

Outro fator importante nesse contexto é o papel de intermediação que ocorre no discurso religioso. Segundo Pulcinelli (1987, p.8), "Do ponto de vista da Análise do Discurso, pode-se dizer que Deus é o lugar da onipotência do silêncio. E o homem precisa desse lugar para colocar (instituir) uma fala específica”. Assim, podemos entender que o homem territorializa a fala de Deus, transformando o silêncio divino em palavras, visto que Deus se manifesta por meio dos homens.

É por intermédio desse discurso que ocorre o contato das pessoas com o plano espiritual, pois normalmente a voz do homem chegará até Deus pela intermediação do sacerdote que, posicionando-se em local próprio, realiza esta intermediação em cerimônias predeterminadas (DIAS, 1987, p. 49). 
Os ritos servem para mostrar a hierarquia do corpo religioso naquelas religiões que existe um corpo sacerdotal que detém o dom de transmitir a palavra sagrada e que, para tanto, foi investido em seus cargos por superiores hierárquicos, que atingiram um estágio superior na graça e na direção da instituição (BOURDIEU, 1996, p. 95).

Outro elemento que aparece implícito, de forma bem dissimulada, como integrante do discurso católico é a coerção que leva o profitente à submissão. Identificase isto na situação do participante dentro do seu credo, uma vez que a sua liberdade está assegurada de acordo com a sua submissão à autoridade e às pregações que devem ser aceitas sem questionamentos. Assim, o profitente possui o livre arbítrio, que deverá, no entanto, ser exercido de acordo com as diretrizes do seu conceito religioso, o que se constitui numa contradição, visto que representa a sujeição do indivíduo, o qual estará sendo, desta forma, coagido. Desse modo, o clero tende a monopolizar o discurso da virtude como forma simbólica de perpetuar a legitimidade da instituição religiosa diante da sociedade (GIL GILHO, 2008, p. 41).

Para Pulcinelli (1996, p. 242), “ o conteúdo da ideologia religiosa se constitui de uma contradição, uma vez que a noção de livre arbítrio traz, em si, a de coerção [...] o funcionamento da ideologia transforma a força em direito e a obediência em dever". A abordagem do bispo D. Mazzarotto mostra essa realidade, ou seja, o alerta, e as punições que os fiéis poderiam receber em participar de atividades espíritas que eram condenadas pela autoridade máxima na diocese.

Para Foucault, o que ocorre normalmente em todas as instituições é um controle sobre os discursos (FOUCAULT, 1996, p. 28). No caso, o discurso religioso é definido por regras e normas que, com um controle hábil, irão determinar o que deve ser publicado, a época ou ocasião em que será colocado a público, ou a que público será destinado. Neste caso, identifica-se essa abordagem no discurso do bispo, que era dirigido a um extenso território abrangendo um grande número de pessoas.

Neste sentido, em sua primeira pastoral, em 1930, afirmava D. Antonio que Cristo anunciou o reino de Deus. Questiona o bispo: "Qual a natureza e extensão deste reino que Jesus fundou e encarregou e Igreja de difundir"? (Pastoral O Reino de Cristo, 1930 p. 6). O reino de Cristo é universal, portanto, material nos templos e imaterial no seu poder espiritual em tamanha dimensão que o homem não consegue imaginar. Assim, o princípio da espacialidade aqui se aplica tanto material como imaterial, 
podendo também ser enquadrado no simbólico.

No Código de Direito Canônico, consta: "Cân. 12 - §1. As leis universais obrigam em todos os lugares a todos aqueles para os quais foram dadas". (C.D.C., 2012, p.32). Em nota explicativa no rodapé, explicita que:

A terminologia deste cânon e do seguinte foi mudada, em relação ao Código anterior, ficando agora mais clara e coerente...: a) Em relação ao território, as leis podem ser universais, se são dadas para o mundo inteiro, ou particulares, se dadas para um território particular (C.D.C., 2012, p. 32, Grifos no original).

Neste princípio, entendemos que o Bispo está falando para a população do seu território, que está sob sua jurisdição.

Nota-se a preocupação com a população da "territorialidade católica" pelas mudanças provocadas na sociedade em função da alteração do regime político, com a implantação da república em território nacional, no final do século XIX. Esse advento provocou, a partir da década de 50 do século $\mathrm{XX}$, uma laicização e secularização religiosa no Brasil a partir da Constituição de 1891, com a separação Estado-Igreja. Esta nova situação causou grande preocupação para a hierarquia católica.

Se num primeiro momento, o discurso voltava-se para combater os espíritas e protestantes, nas décadas que se sucederam aumentou o grau do perigo, com o surgimento dos evangélicos e neoevangélicos, o que se tornou um complicador a mais para a hierarquia católica. Em face disso, exigiram-se destas ações que se sobrepusessem às novas ideologias religiosas que se instalavam em território brasileiro.

Nas primeiras décadas do século XX, a hierarquia da Igreja reagiu à nova situação política que se apresentava pelas mudanças na sociedade através de movimentos e convulsões políticas, sociais e culturais.

Essa reação, que teve origem com o Decreto 119-A, de 17 de janeiro de 1890, determinou a separação Estado-Igreja. Somem-se outras manifestações na década de 1920, culminando com a Revolução de 1930.

Releve-se que desde o final do século XIX a Igreja iniciou uma reação à nova situação política e social no território brasileiro. Na capital da República, Rio de Janeiro, D. Sebastião Leme da Silva Cintra (1880-1942) realizou um grande trabalho na organização e atração de intelectuais leigos, fundando, para tanto, o Instituto D. Vital, 
com o objetivo de combater o laicismo e a secularização da sociedade, bem como as religiões que estavam surgindo.

Dentro das grandes preocupações, já figurava o Espiritismo, crença que já era discriminada e combatida tanto em países da Europa como nos Estados Unidos (PRIORE, 2014, p. 131-133). No Brasil Império, teve início o discurso católico contra o Espiritismo, que se estendeu pela República, de forma oficial, até o Concílio Vaticano II (1962-1965). A reação e oposição ao Espiritismo partiu de setores religiosos e leigos. O Vaticano condenou as práticas dessa doutrina, tendo como mote principal a "metempsicose" ou reencarnação, por este princípio negar: céu, inferno, limbo, purgatório, dogmas sagrados para a Igreja.

A nova Diocese de Ponta Grossa não ficou à margem das ações, o que se identifica pelo discurso de D. Mazzarotto de combate ao Espiritismo e a manutenção dos fiéis sob o aprisco da Igreja.

Analisando pela premissa do início da década de 1930, o bispo talvez não conseguisse dimensionar a extensão do território da sua Diocese. Portanto, parte para uma representação simbólica da divindade, bem como da sua autoridade, impondo esta autoridade pelo princípio da sua força e liderança religiosa de pastor, que foi divinamente autorizado pelo Sumo Pontífice. Como sua presença não pode ser constante perante a diversas paróquias, entendemos que busca o culto e o respeito à sua pessoa enquanto líder e autoridade máxima dos católicos da diocese, de forma simbólica, pela divulgação da sua palavra através das suas Pastorais e dos párocos.

Demonstrando a preocupação com seu "rebanho" e alertando para que não se afastassem do aprisco católico, o bispo determinava para os membros da sua Diocese:

Repeli todas as manifestações do espiritismo. Esta superstição que é a mais danosa das pestes que se vai inoculando traiçoeiramente na vida religiosa do povo, é forte laço com que o espírito das trevas tem engenhado enredar as almas menos avisadas, arrastá-las para fora do aprisco católico e daí para a condenação eterna. Deixo de acenar ao cortejo de males que neste mundo acompanha amiúde os que praticam o bruxedo espirítico. (Pastoral O REINO DE CRISTO, 1930, p. 15).

Observemos os detalhes embutidos no discurso. O autor do discurso é a autoridade máxima católica na diocese, dirige uma instituição considerada por ele como 
sagrada e santa, criada pelo próprio Cristo. O contexto do discurso, mesmo nas pastorais subsequentes, é de exaltação da sua instituição em detrimento do Espiritismo "bruxulento, herético e diabólico". Não esqueçamos que é nesta década que, no Rio de Janeiro, tem início o trabalho de restauração da Igreja, em termos religioso e político. Este trabalho foi chamado de "Renascimento Católico" (MORAIS, 1986, p. 7), e também de "Restauração Católica" (AZZI, 1994 p. 23). Estas ações foram desenvolvidas pelo Cardeal D. Leme, repercutindo, influenciando e motivando as demais autoridades católicas no Brasil.

O uso e o simbolismo da figura do diabo e todas as suas outras denominações é uma prática recorrente nos discursos católicos das décadas finais do século XIX e até a década de 60 do XX, principalmente no que chamavam de combate às heresias. Com o Espiritismo não foi diferente, tanto na palavra dos bispos, padres e leigos. Pudemos comprovar isso quando do nosso doutorado, onde analisamos os discursos católico e espírita, na República brasileira até o Concílio Vaticano II (1962-1965). ${ }^{1}$

O objetivo do discurso é proteger e alertar que a igreja Católica é o refúgio seguro para as tentações demoníacas do Espiritismo. É na figura dos bispos e sacerdotes que os profitentes encontrarão o esclarecimento e a proteção necessária. Para Isaia,

[...] o discurso da hierarquia católica pré-conciliar, essa simplificação, e radicalização era construída a partir de vários pares antitéticos, nos quais se contrapunham a perene "verdade", custodiada pela Igreja, e as falsidades e maquinações do inimigo sempre visível no mundo descristianizado: maçons, anarquistas, comunistas, protestantes (ISAIA, 2012, p. 135).

Ao mesmo tempo que alertava, constava no mesmo uma abordagem atemorizante e ameaçadora dos castigos que adviriam para aqueles que se afastassem do aprisco católico ou frequentassem o Espiritismo ou a umbanda. Estas duas últimas citadas, pela menor estrutura, poder econômico e de tradição perante à dominante católica, surgem como dominadas no contexto social como religião inferior, no caso do Espiritismo: "religião inferior e contemporânea" (BOURDIEU, 1992, p. 43). Continuava D. Antonio ao dirigir-se ao seu "rebanho":

\footnotetext{
${ }^{1}$ Demônios e Anjos. (O embate entre espíritas e católicos na República brasileira até a década de 60 do século XX).
} 
[...] resisti a essa serpente infernal, sem nunca se terem deixado infeccionar pela sua baba venenosa, sejam essas nossas letras um amoroso aviso paterno para que se premunam contra essa armadilha com que o demônio tem aprisionado tantas almas, desgraçando-as nesta vida e muito mais na outra. (Pastoral A MAGIA ESPIRITICA, 1932, p. 4, Grifo nosso).

Observa-se o simbolismo do além, nas penas que estariam esperando pelos que debandassem do aprisco da Igreja para a heresia do Espiritismo, pois a vida espiritual é eterna, então as penas seriam eternas, e o porto seguro era a Igreja.

Assim, de acordo com sua sacralidade, a Igreja surge como o espaço sagrado e protetor do simbolismo de sua autoridade. Neste sentido de espaço, não só o territorial, mas também o simbólico, visto estar o bispo dirigindo seu discurso para um grande número de pessoas, em um grande território que abrangia o território da sua diocese. Abordava, ainda, D. Antonio: "Com o ouro dos protestantes e com a filantropia dos espiritistas, compram-se as consciências e semeia-se o erro contra a única depositária da sã doutrina e a mestra infalível da verdade, a Santa Igreja Católica" (Pastoral MANANCIAL DE GRAÇAS, 1945, p. 8).

Este discurso contra os espíritas surge como um alerta e esclarecedor, com um fundo psicológico, haja vista que as penas e promessas de excomunhão, que resultariam em penas eternas irreversíveis, vem no sentido de criar um clima de medo, temor e pavor dos castigos para aqueles que entrassem em contato com a heresia. No sentido da religião, Jung afirma que:

Visto que a religião constitui, sem dúvida alguma, uma das expressões mais antigas e universais da alma humana, subentende-se que todo o tipo de psicologia que se ocupa da estrutura psicológica da personalidade humana deve pelo menos constatar que a religião, além de ser um fenômeno sociológico ou histórico, é também um assunto importante para grande número de indivíduos (JUNG, 2016, p. 17).

Este sentido psicológico para as pessoas provavelmente provocou grande aflição entre os habitantes da diocese de Ponta Grossa, acrescentando as afirmações dos males físicos e mentais que o Espiritismo poderia provocar nos seus adeptos. Para tanto, o bispo cita publicações de psiquiatras das primeiras décadas do século $\mathrm{XX}$, como os doutores Xavier de Oliveira, Leonídio Ribeiro e Murilo Campos. Com base nestes 
psiquiatras, afirmava:

A maior parte dos médiuns mais famosos e não poucos dos que se distinguem como assíduos cultivadores das práticas espiríticas ou estão loucos ou são nevropatas ou vítimas de paralisias progressivas [...] o espiritismo é um poderoso fator de desiquilíbrio mental, concorrendo poderosamente com $\mathrm{o}$ alcoolismo e a sífilis para povoar os hospícios de alienados. (Pastoral A MAGIA ESPIRITICA, 1932, p. 23).

Observa-se que o sentido é de implantar o medo individual e coletivo a que os fiéis católicos eram submetidos. Perante as ameaças demoníacas, o único abrigo imaginável é a religião, com sua hierarquia e seu corpo sacerdotal. Segundo Delumeau, "Nada é mais difícil de analisar do que o medo, e a dificuldade aumenta ainda mais quando se trata de passar do individual ao coletivo" (DELUMEAU, 1989, p. 22). A situação do profitente (individual) perante a autoridade e a comunidade (coletivo) tornase difícil em não acatar as orientações do líder eclesiástico, bem como a discriminação que passaria a sofrer perante o espaço em que habita, ou sua comunidade. Cria-se um sentido de cumplicidade e vigilância em pequenas comunidades sobre o comportamento dos membros do grupo, gerando um medo psicológico e escatológico, perante as penas previstas no discurso de D. Mazzarotto.

Recordemos, os castigos podem ser materiais, imateriais/simbólicos. Os materiais compreendem o ridículo perante à comunidade, a excomunhão e outras formas. O espaço simbólico imaterial, o não visível, é representado pelo espiritual com penas eternas. Para isso, estão associados às figuras demoníacas e ao fogo eterno do inferno, pintados em cores vibrantes, como forma de punir severamente aqueles que se desgarrarem dos ensinamentos da Igreja. Assim, constrói-se o pavor e o medo pelo desconhecido.

Visto pela premissa do medo do imaterial ou espiritual, ou do mundo simbólico, o imaterial é um espaço simbólico imaginário, do qual não é possível mensurar a sua extensão, por isso mesmo essa representação causa tanta preocupação no campo religioso. Fala-se muito deste espaço não terrestre, mas não se pode explicar de forma empírica como ele está organizado. No caso da Igreja, são três níveis - paraíso, purgatório e inferno. Como estão organizados? Mesmo com a imagem de que o paraíso é um ótimo lugar, não se pode afirmar que as pessoas tinham ou tenham vontade de 
conhecê-lo.

Le Goff cita um adágio popular medieval: "Bem-vindo o paraíso, mas o mais distante possível” (LE GOFF, 1981, p. 15). Não há pressa para conhecê-lo, mesmo com a imagem de uma vida venturosa, se para esse não há pressa, que dirá para os outros dois, que apareciam com penas duríssimas e sofrimentos inenarráveis eternos. A esses mundos imateriais Le Goff vai afirmar que eles compõem uma "geografia do além". (LE GOFF, 1981, p. 180). A essa geografia podemos identificar um espaço imaterial sagrado dotado de um grande simbolismo que não pode ser dimensionado, ou "o espaço das representações simbólicas” (GIL FILHO, 2008, p. 73).

Continuando na sua abordagem demoníaca e dos castigos, D. Antonio aborda que

Os espíritas são, além de supersticiosos, hereges e fautores de hereges, apóstatas da Fé católica e como tais incorrem na excomunhão maior reservada especialmente ao Sumo Pontífice. Declara mais a igreja, nossa mãe, que não se pode de modo algum assistir as sessões espiríticas, ainda que seja por simples curiosidade. (Pastoral A MAGIA ESPIRÍTICA, 1932, p. 24-25).

Novamente, eis o discurso de coerção para os fiéis e também do pavor que aquelas práticas podem causar, tanto material como espiritual.

Observamos uma abordagem que expõe alertas para os dois planos, o material/empírico e o espiritual/imaginário/simbólico. O discurso, como já nos referimos, é produzido para divulgação entre os fiéis. Os mesmos tomarão conhecimento dele através dos sacerdotes nas paróquias e capelas existentes no espaço territorial da diocese. As paróquias são a base da diocese, onde são desenvolvidas todas as atividades sagradas (cerimônias religiosas) e profanas (festas/comemorações), pois formam o núcleo para onde convergem os fiéis. "É nas paróquias que reside a dinâmica social da Igreja e seu próprio final, ou seja, elas são a escala local, na qual todas as realidades da ação institucional católica, veiculadas pelo discurso, encontram suas realizações" (GIL FILHO, 2008, p. 122). Assim, os membros participantes encontram na paróquia seu locus de identificação com a religião e a vivência em comunidade.

É neste espaço da paróquia que representa "a materialidade da ação evangelizadora e também à territorialidade materializada e legitimada pela ação do 
poder institucional sob forma de território" (GIL FILHO, 2008, p. 122). Este espaço paroquial representa a descentralização hierárquica da Igreja, pois é a célula que está em contato constante com a comunidade, sempre submetida a autoridade eclesiástica, no caso os "BISPOS".

Com seu discurso, o bispo representa a mensagem de Deus para seus subordinados e fiéis. Como já citado, sua autoridade está assegurada pela unção do Sumo Pontífice e pelo Código de Direito Canônico, portanto, inquestionável. Desta forma, o discurso religioso deve ser caracterizado "como aquele em que fala a voz de Deus: a voz do padre - ou do pregador, ou em geral de qualquer representante seu - é a voz de Deus" (ORLANDI, 1996, p. 243). A sua fala, enquanto autoridade, tem que ser aceita como verdade, pois essa se transforma numa pregação ideológica religiosa e deve ser aceita. Ou seja, o discurso do Bispo representa a voz da Igreja e encarna a voz da divindade contra aqueles que se opõem à instituição sagrada que ele representa.

Esses opositores renitentes à sua pregação, no espaço territorial da Diocese de Ponta Grossa, são os Espíritas. Esta oposição ao discurso do bispo deve ser, sob esta concepção, condenada e seus seguidores classificados como "hereges e fautores de heresia", respondendo pelo pecado de desrespeito à autoridade do Bispo.

\section{Referenciais}

AZZI, Riolando. A Neocristandade um o projeto restaurador. São Paulo: Paulus, 1994.

BARBOSA, Pedro Franco. Espiritismo básico. 3. ed. Rio de Janeiro: Federação Espírita Brasileira, 1987.

BERGER, Peter Ludwig. O Dossel sagrado: Elementos para uma teoria sociológica da religião. Trad. José Carlos Barcellos. São Paulo: Paulinas, 1985.

BOURDIEU, Pierre. A economia das trocas simbólicas. Trad. Sergio Miceli. São Paulo: Perspectiva, 1992. 1996.

A economia das trocas linguísticas. Trad. Sergio Meceli. São Paulo: EDUSP,

CDC. Código de Direito Canônico. 12. ed. Trad. Conferência nacional dos Bispos do Brasil. São Paulo: Loyola, 2012.

CONTE-SPONVILLE, André. O espírito do ateísmo. Introdução a uma espiritualidade sem Deus. Trad. Eduardo Brandão. São Paulo: Martins Fontes, 2007.

COSTA, Flamarion Laba da. Trabalho, Solidariedade e Tolerância. (A Sociedade Espírita Francisco de Assis de Amparo aos Necessitados 1912-1989). Curitiba, 1995. 
Dissertação de (Mestrado em História). Setor de Ciências Humanas, Letras e Artes. Universidade Federal do Paraná. Curitiba, 1995.

Demônios e Anjos. (O embate entre espíritas e católicos na República brasileira até a década de 60 do século XX). Curitiba, 2001. Tese de (Doutorado em História). Setor de Ciências Humanas, Letras e Artes. Universidade Federal do Paraná. Curitiba, 2001.

DEL PRIORE, Mary. Do outro lado. A história do sobrenatural e do espiritismo. São Paulo: Planeta, 2014.

DELUMEAU, Jean. História do medo no ocidente 1300-1800. Uma cidade sitiada. Trad. Maria Lucia Machado. São Paulo: Companhia das Letras, 1989.

DUPRONT, Alphonse. A religião: Antropologia religiosa. In: LE GOFF, Jacques; NORA, Pierre. História: novas abordagens. Trad. Henrique Mesquita. Rio de Janeiro: Francisco Alves, 1976.

DURKHEIM, Émile. As formas elementares da vida religiosa. O sistema totêmico na Austrália. Trad. Paulo Neves. São Paulo: Martins Fontes, 2003.

ELIADE, Mircea. O sagrado e o profano. A essência das religiões. Trad. Rogério Fernandes. São Paulo: Martins Fontes, 1992.

FILORAMO, Giovanni. PRANDI, Carlo. As ciências das religiões. Trad. José Maria de Almeida. São Paulo: Paulus, 1999.

FOUCAUlT, Michel. A ordem do discurso. 2. ed. Trad. Laura Fraga e Almeida Sampaio. São Paulo: Loyola, 1996.

GIL FILHO, Sylvio Fausto. Espaço sagrado: estudos em geografia da religião. Curitiba: Ibpex, 2008.

ISAIA, Artur Cesar. MANOEL, Ivan Aparecido (Orgs.). Espiritismo e religiões afrobrasileiras. São Paulo: UNESP, 2012.

JUNG, Carl Gustav. Psicologia e religião. 11. ed. Trad. Pe. Dom Mateus Ramalho Rocha. Petrópolis: Vozes, 2012.

LE GOFF, Jacques. O nascimento do purgatório. Trad. Maria Fernanda Gonçalves de Azevedo. Lisboa: Editorial Estampa, 1981.

MORAIS, Régis. In: ARAUJO, José Carlos Souza. Igreja Católica no Brasil. São Paulo: Paulinas, 1986.

MÜLLER, Max. La ciencia de la religion: Origen y desarrollo de la religion. Buenos Aires: Editorial Albatros, 1945.

ORLANDI, Eni Pulcinelli. A linguagem e seu funcionamento: As formas do discurso. 4. ed. Campinas: Pontes, 1996.

ORLANDI, Eni Pulcinelli. (Org.). Palavra, Fé e Poder. Campinas: Pontes, 1987.

OTTO, Rudolf. O sagrado. Trad. João Gama. Lisboa: Edições 70, 2005.

PASTORAL A magia espiritica. 1932. Curityba: Typographia A Cruzada.

PASTORAL Manancial de graças, 1945. Sem citação de tipografia e cidade. 
PASTORAL O reino de Christo, 1930. Roma: Tip. Cons. Nazionale.

PEREIRA, Clevisson Junior. Geografia da religião e a teoria do sagrado: a construção de uma categoria de análise e o desvelar de espacialidades do protestantismo Batista. Curitiba: Editora CRV, 2014.

WEBER, Max. Ensaios de sociologia. 5. ed. Trad. Waltensir Dutra. Rio de Janeiro: Guanabara Koogan, 1982.

Recebido: $15 / 11 / 2016$

Received: $11 / 15 / 2016$

Aprovado: 09/12/2016

Approved: 09/12/2016 